\title{
Determination of optimum parameters using grey relational analysis for multi-performance characteristics in $\mathrm{CO}_{2}$ laser joining of dissimilar materials
}

\author{
K.F. Tamrin ${ }^{\mathrm{a}, \mathrm{c}, *}$, Y. Nukman ${ }^{\mathrm{a}}$, N.A. Sheikh ${ }^{\mathrm{b}}$, M.Z. Harizam ${ }^{\mathrm{a}}$ \\ a Department of Mechanical Engineering, Faculty of Engineering, University of Malaya, 50603 Kuala Lumpur, Malaysia \\ ${ }^{\mathrm{b}}$ Department of Mechanical Engineering, Mohammad Ali Jinnah University, Islamabad, Pakistan \\ ' Advanced Technovation Ltd., Loughborough Innovation Centre, Loughborough University Science E' Enterprise Park (Holywell Park), \\ Loughborough, LE11 3AQ, UK
}

\section{A R T I C L E I N F O}

\section{Article history:}

Received 2 October 2013

Received in revised form

31 December 2013

Accepted 9 January 2014

Available online 30 January 2014

Keywords:

Laser lap joining

Laser welding

Dissimilar materials

Glass-ceramic

Joint strength

\begin{abstract}
A B S T R A C T
This study concerns the employment of grey relational analysis to determine the optimized joint characteristics in $\mathrm{CO}_{2}$ laser lap joining of dissimilar materials classes. The joint characteristics, namely weld strength, weld width and kerf width are optimized as a function of laser power, its stand-off distance and the speed of welding. Due to a number of experimental constraints pertaining to joining polymer and glass-ceramic substrates, a full-factorial experiment is considered. Detailed images of the welded samples show the formation of crystallized glass leading to the failure of the joint. Thereafter, grey relational analysis (GRA) is employed to characterize the multiple quality characteristics of welded joint in terms of a relational grade. The set of the optimized processing parameters is determined based on the highest grade at $40 \mathrm{~W}$ laser power with a welding speed of $10 \mathrm{~mm} / \mathrm{s}$ at a stand-off distance of $37 \mathrm{~mm}$. Analysis of variance (ANOVA) is then carried out to ascertain the relative influence of process parameters on the joint characteristics. It was found that the weld speed has dominant effect on joint characteristics in comparison to stand-off distance at a fixed laser power.
\end{abstract}

(c) 2014 Elsevier Ltd. All rights reserved.

\section{Introduction}

The demand for efficient, low cost and reliable products has encouraged the use of non-conventional manufacturing processes and non-metallic materials. The objective of achieving functional and smart micro-electro-mechanical systems (MEMS) sensors has led to the extensive use of combined materials constitute of polymers, glass, metal and ceramic that can sustain high-temperatures, fluctuating pressures and oxidation/corrosion surroundings. MEMS based sensors have gained particular importance due to limited capabilities of silicon-based sensors in adverse conditions. However processing of these materials can be delicate especially while joining two or more dissimilar materials due to large differences in chemical and physical properties.

In recent year's use of Lasers in manufacturing processes has increased considerably. Compared to conventional techniques it offers a number of advantages. For instance conventional welding techniques such as gas tungsten arc welding offer reliability but

\footnotetext{
* Corresponding author at: Department of Mechanical Engineering, Faculty of Engineering, University of Malaya, 50603 Kuala Lumpur, Malaysia. Tel.: +601115653090; fax: +60379675330.

E-mail addresses: fikri@um.edu.my, krolfikri@yahoo.co.uk (K.F. Tamrin).
}

may lead to significantly larger heat affected zone (HAZ). On the other hand, laser joining leads to localised non-contact thermal heating process resulting in small heat-affected zone. In addition, it allows materials to be welded where accessibility is virtually difficult especially in MEMs packaging and micromachining.

In a typical laser lap joining process, the top material is usually transmissive while material at the bottom is absorptive. At the interface, as a result of generated heat and subsequent localized melting, a joint is created. The selection of the type of laser and its optimum operating parameters is dependent on material's absorptivity at a particular wavelength and is often responsible for achieving strong weld joint. For joining dissimilar materials, various types of lasers have been used such as Nd:YAG, diode and fibre lasers at various combination of power (or energy) and wavelength. For instance, Wahba et al. [1] investigated the use of a $700 \mathrm{~W}$ diode laser $(807 \mathrm{~nm}$ ) to weld thixomolded $\mathrm{Mg}$ alloy and polyethylene terephthalate (PET). In their investigation, high joint strength was characterised by bubbles expansion of different morphologies. An increase by $15 \%$ was reported if the alloy is grounded prior to joining, creating non-structured pores that allow melted plastic to flow into and consequently form an additional mechanical anchor effect. On the other hand, Mian et al. [2] utilised a significantly low power of $2.2 \mathrm{~W}$ fibre laser 